\title{
Statistical analysis of concrete strength variability for quality assessment: Case study of a Saudi construction project
}

\author{
Mohamed Aichouni *, Noureddine Ait Messaoudene, Mabrouk Touahmia, Abdulaziz Al-Ghonamy
}

College of Engineering, University of Hail, Hail, Saudi Arabia

\section{A R T I C LE IN F O}

\section{Article history:}

Received 19 March 2017

Received in revised form

18 May 2017

Accepted 2 June 2017

\section{Keywords:}

Concrete

Compressive strength

Statistical analysis

Quality tools

Process improvement

\begin{abstract}
A B S T R A C T
Quality control in ready-mixed concrete industry is increasingly emerging as a tool for achieving highest quality at lowest cost. In typical construction projects, compressive strength is the most important criterion for assessing the acceptability of a concrete batch from a given plant. Variability in compressive strength of concrete batches is inevitable in practice. This has lead researchers in the field of quality control to analyze the statistics of strength results in order to draw conclusions about quality level in concrete plants and ways to improve it. In the present research the quality of concrete materials is examined using well established quality control tools and techniques. The main objective of the study is to identify and evaluate opportunities for improvement in concrete production processes and in pouring methods of concrete. The results showed that management should set systematic procedures using quality tools such as histograms, control charts and fishbone diagrams, to analyze concrete strength data and detect any abnormal variation.
\end{abstract}

(C) 2017 The Authors. Published by IASE. This is an open access article under the CC BY-NC-ND license (http://creativecommons.org/licenses/by-nc-nd/4.0/).

\section{Introduction}

Concrete is the most widely used material in construction industry. It is important to understand and find engineering approaches and ways to improve the quality of this product at production plants and construction sites as well as to reduce cost. In typical construction projects, compressive strength is the most important criterion in assessing the acceptability of a concrete batch supplied by any given plant. Variability in compressive strength of the concrete batches from any plant is inevitable. Sources of such variability range from errors in proportion measurement of the batch ingredients to the variation in the properties of these ingredients (Day et al., 2013; Obla, 2010).

On the other hand, variability has an important impact on improving quality in general and variability in concrete mechanical properties can have a direct impact on structural parameters such as seismic performance (De Stefano et al., 2014). Such variability has lead researches in the field of quality control to analyze the statistics of compressive strength in order to draw conclusions

\footnotetext{
* Corresponding Author.

Email Address: m.aichouni@uoh.edu.sa (M. Aichouni) https://doi.org/10.21833/ijaas.2017.07.015

2313-626X/C) 2017 The Authors. Published by IASE.

This is an open access article under the CC BY-NC-ND license

(http://creativecommons.org/licenses/by-nc-nd/4.0/)
}

about process quality in suppliers' plants. Statistical parameters such as standard deviation of compressive concrete strength and bias in its mean are the primary indicators in such analyses. Previous studies have shown interesting results concerning the statistical variability in concrete production plants (Laungrungrong et al., 2009).

Quality tools and techniques have been used by quality professionals to identify procedures, ideas, statistics, cause and effect relationships and other issues relevant to constructions projects quality (Banawi and Bilec, 2014). They can be used to enhance the effectiveness, efficiency, standardization and overall quality of procedures, products, services and work environment, in accordance with ISO 9000 standards. These tools and techniques have been used in organizations to assist in the analysis, documentation and organization of quality systems. They have also been used as problem solving and process improvement tools (Dias and Saraiva, 2004).

Recent studies have demonstrated the effectiveness of these tools for construction processes improvement, problem solving and achievement of customer satisfaction in many construction organizations (ReVelle and Margetts, 2010; Lobo, 2006). Special focus has been devoted in the literature to the use of the seven basic quality tools, such as histograms and control chart tools, for the improvement of different construction processes 
including concrete production (Sarkar and Dutta, 2009; Gibb and Harrison, 2010).

\section{Concrete strength variability and acceptance criteria}

\subsection{Strength variability}

Ready mix concrete is a mixture of several constituents such as water, cement, aggregate, air and ad-mixtures. Variations in the properties or proportions of these constituents, as well as variations in transporting, placing, and compaction of the concrete, lead to variations in the strength of the finished product (ACI, 2005; SBC, 2007; Laungrungrong et al., 2009).

To these factors influencing concrete variability can be added variations in other components of the production system such as machines, manpower, construction practices and methods, and measurements. Chen et al. (2014) have attempted to model the variability of concrete elements and have validated a number of models.

According to the ASTM (2015) and SBC (2007), the standard test for measuring the strength of concrete involves a compression test on cylinders (150 $\mathrm{mm}$ in diameter and $300 \mathrm{~mm}$ high) after they are made and cured for 28 days.

A sufficient number of tests are needed to accurately capture variations in the concrete and allow using appropriate statistical procedures for interpreting the test results. Statistical tools provide a sound basis for determining the quality and strength of the concrete from such results and for expressing results in the most useful form.

\subsection{Strength variability and classification of concrete according to ACI 214-2005}

Variation in compressive strength as measured by standard deviation $(\sigma)$ can be used as a measure of a concrete producer's level of quality control (QC). Day et al. (2006) and Laungrungrong et al. (2009) suggest the possibility of considerable savings on materials and costs for concrete producer who attains lower values of standard deviation associated with acceptable values of coefficient of variation. Achieving such goal requires a good understanding of the sources of concrete strength variation using appropriate statistical methods and quality improvement tools (ACI, 2005).

In order to improve concrete quality, strength standard deviation should be reduced and this can only be achieved through the reduction of variability in materials, manufacturing process and testing methods. But first, a thorough assessment of variability through an analysis of concrete test results should be carried out using appropriate quality tools and process improvement techniques such as histograms, control charts and other advanced statistical tools (ACI, 2005).

\section{Statistical analysis of the quality of the concrete poured in the project}

\subsection{Data description}

Data provided by the contractor of an important construction project in Saudi Arabia for concrete supplied by three suppliers denominated S1, S2 and S3 consisted of compressive strength test results reported in monthly or weekly reports. It has to be noted here that among the huge amount of data provided by the contractor for the three suppliers, only samples of the data were analyzed due to the fact that data was in paper form. As stated by ACI (2005) and SBC (2007), for accurate and valid statistical analysis, compressive strength data should be derived from samples obtained by means of a random sampling plan designed to reduce the possibility that selection will be exercised by the sampler.

Sufficient data have been gathered from the three suppliers' records of tests certificates for different types of concrete (C25, C50 and C65) poured in the project. It is to be noted here that in $\mathrm{C} 25,25$ stands for the design mix having a characteristic compressive strength of $25 \mathrm{MPa}$ at concrete age of 28 days. The compressive strength tests at 28 days were performed by third parties accredited testing laboratory as required by ASTM $(2015,2017)$ and SBC (2007). Herein according to ACI (2005), the following are supposed:

- $f_{c}^{\prime}$ : Specified compressive strength (MPa);

- Strength test result: the average of two or more single-cylinder strengths of specimens made from the same concrete sample (companion cylinders) and tested at the same age.

\subsection{Data analysis}

According to ACI (2005) (chapter 5), strength data analysis is required in many real field situations. The commonly required applications are: (a) to determine compliance with specifications; (b) to evaluate the level of control on the production process (typically called statistical quality control); (c) to identify opportunities for improvement.

In order to achieve the objectives listed above, strength data are analyzed using quality tools in the sequences shown in Fig. 1.

Quality tools, especially histograms and control charts, have found widespread use in the construction industry in both ready-mixed concrete and asphalt production plants. In particular, control charts have been applied to monitor a range of product characteristics (e.g. cube/cylinder strength, consistence, $\mathrm{w} / \mathrm{c}$ ratio), constituent materials (aggregate grading, cement strengths etc.) or production (batching accuracy). Such tools are described in the ACI (2005) standards and technical papers (Sarkar and Dutta, 2009; Gibb and Harrison, 


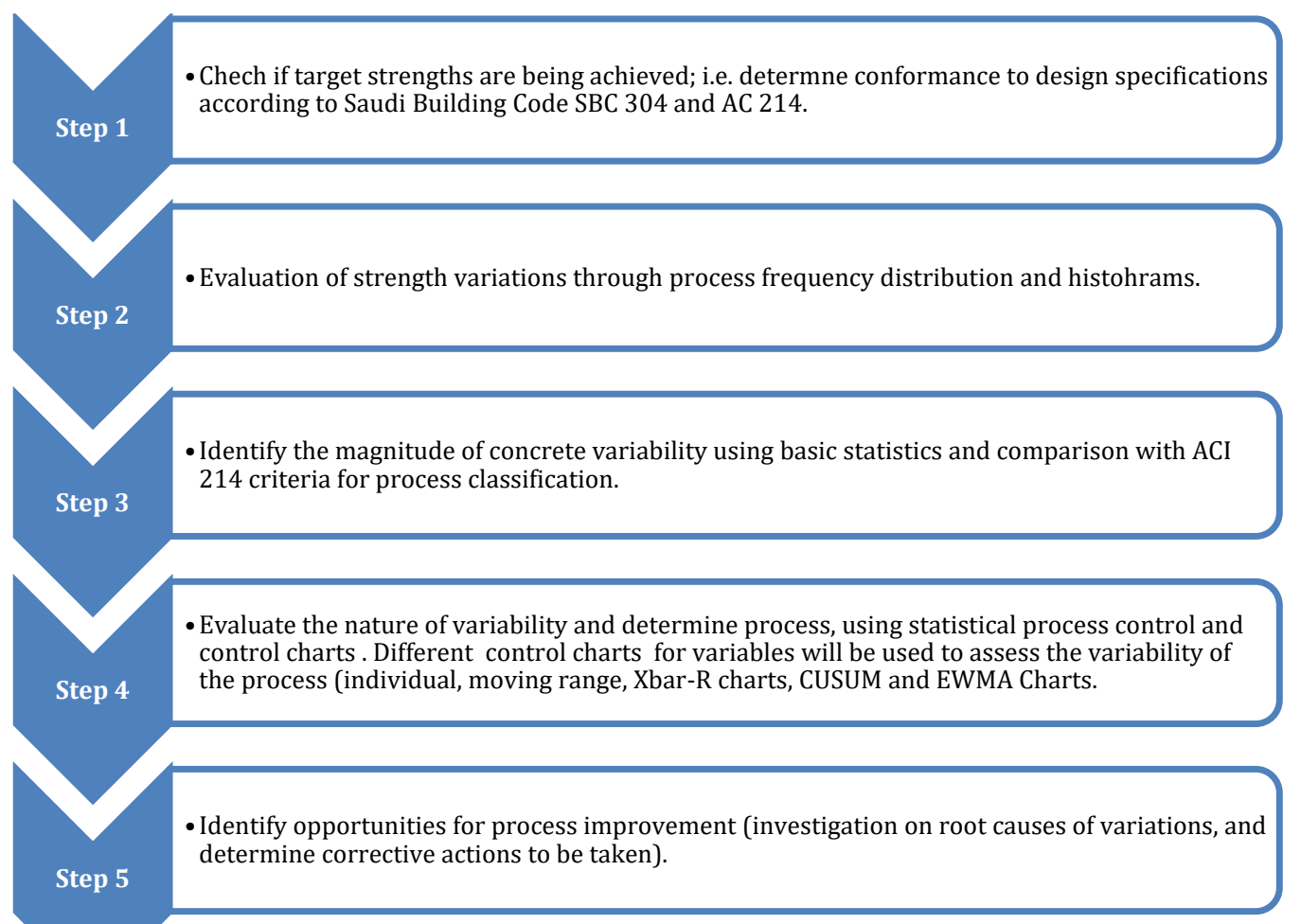

Fig. 1: Steps of the statistical analysis of concrete strength data

\section{Results and discussion}

\subsection{Assessment of the quality of the concrete (conformance ET specifications)}

Any batch of concrete is produced based on a mix design aiming to achieve a nominal strength value $f_{c}{ }^{\prime}$ specified by the structural designer. An optimum result of the concrete production is a batch with all cylinders giving compressive strength exactly equal to $f_{c}^{\prime}$. Realistically, the tested strength of concrete samples will differ from $f_{c}^{\prime}$, some lower than $f_{c}{ }^{\prime}$ and some higher. Lower values may pose a risk on the structural element the concrete is used for construction. This risk is meant to be reduced by using the strength reduction factors in design. A typical design requirement is to allow no more than $10 \%$ of the strength tests to fall below $f_{c}{ }^{\prime}$ (ACI, 2005; SBC, 2007).

The primary objective of the statistical analysis of concrete strength data is to assess the quality of the concrete poured in the project and to check that the poured concrete conforms to the design specifications of project owner. Fig. 2 presents the variation of the strength test results as defined by the ACI (2005) standards for all types of concrete supplied by all three suppliers. It can be shown that:

- All the delivered concrete strength as measured by the strength test result falls well above the specified compressive strength $f_{c}{ }^{\prime}$.

- No individual strength test result falls below the specified compressive strength $f_{c}{ }^{\prime}$ for all types of concrete supplied to the project by all three suppliers.

- The delivered concrete to the project by the three suppliers, meets the general acceptance criterion as stated by ACI (2005) and SBC (2007).

From the statistical analysis of the test strength results, it can clearly be stated that as far the compliance with contract specifications, the delivered concrete by all three suppliers meets the specifications of SBC (2007) and ACI (2005) criteria of concrete acceptance.

\subsection{Evaluation of the magnitude of concrete variability and process classification}

ACI (2005) specifies that data analysis is based on values $\mathrm{X}_{\mathrm{i}}$, designated strength test results, defined as the average of three cylinders strength tests. However, process variability is better assessed if one uses individual single-cylinder strength by comparison to any general manufacturing processes. Here a concern was raised regarding the accuracy and the validity of the analysis. Fig. 3 shows that process distribution is almost identical in the two situations where $X_{i}=$ Strength Test results is the average of three cylinders from the same batch of concrete (dashed line), and $\mathrm{X}_{\mathrm{i}}$ is the individual test data taken from test certificates (solid line). Nevertheless, data from supplier S3 (Fig. 3c) exhibits a small difference between the distributions probably due to the existence of outlier values in the concrete strength. Thus, the distribution obtained 
from the individual test data seems to be more realistic for capturing variability. The last option was adopted in previous studies in Arizona state university led by Laungrungrong et al. (2009). Therefore, it can be argued that analyzing all the individual cylinder strengths would lead to more accurate informative process distribution and overall process variability. Consequently, all forthcoming discussion will deal with individual test data as taken from the laboratory tests certificates.

Referring to Fig. 3, it can be shown that the strength of the concrete delivered to the project far exceeded the specified strength values. This observation can clearly be seen from Fig. 2 for the three suppliers. Furthermore, it can clearly be seen that some variation in concrete strength does exist and its magnitude differs between the three

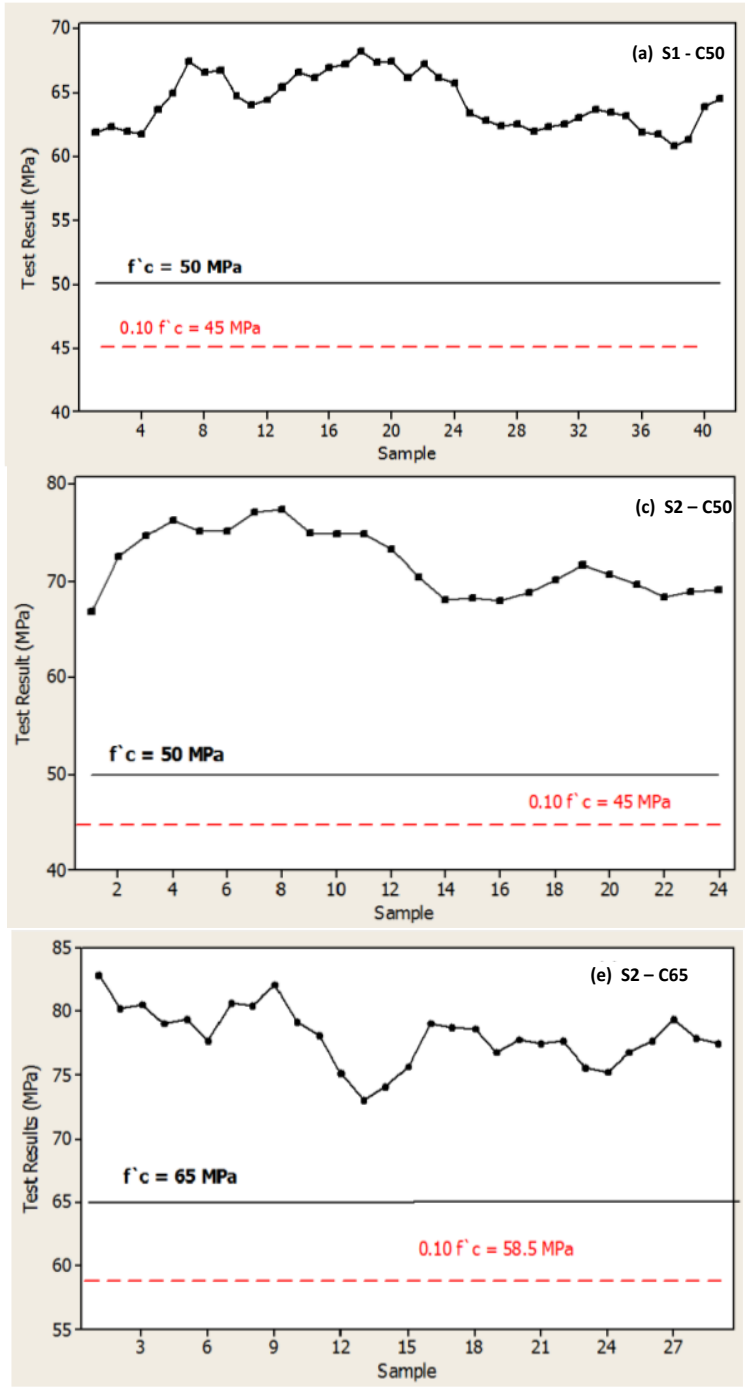

suppliers. Concrete strength variation is discussed in ACI (2005) (chapter 2 and 3) and statistical methods and quality tools can be used to evaluate and analyze it.

The magnitude of variations in concrete strength is a direct result of the degree of control exerted over its production process, its constituent materials, transportation process, sampling, and testing procedures.

It can be inferred that proper analysis of variation using appropriate statistical tools offers a potential for reducing cement consumption, thus contributing to sustainable concrete fabrication. In a previous study, Laungrungrong et al. (2009) analyzed concrete data provided by Arizona Department of Transportation (ADOT); they have noticed the same observations as in the present concrete data.
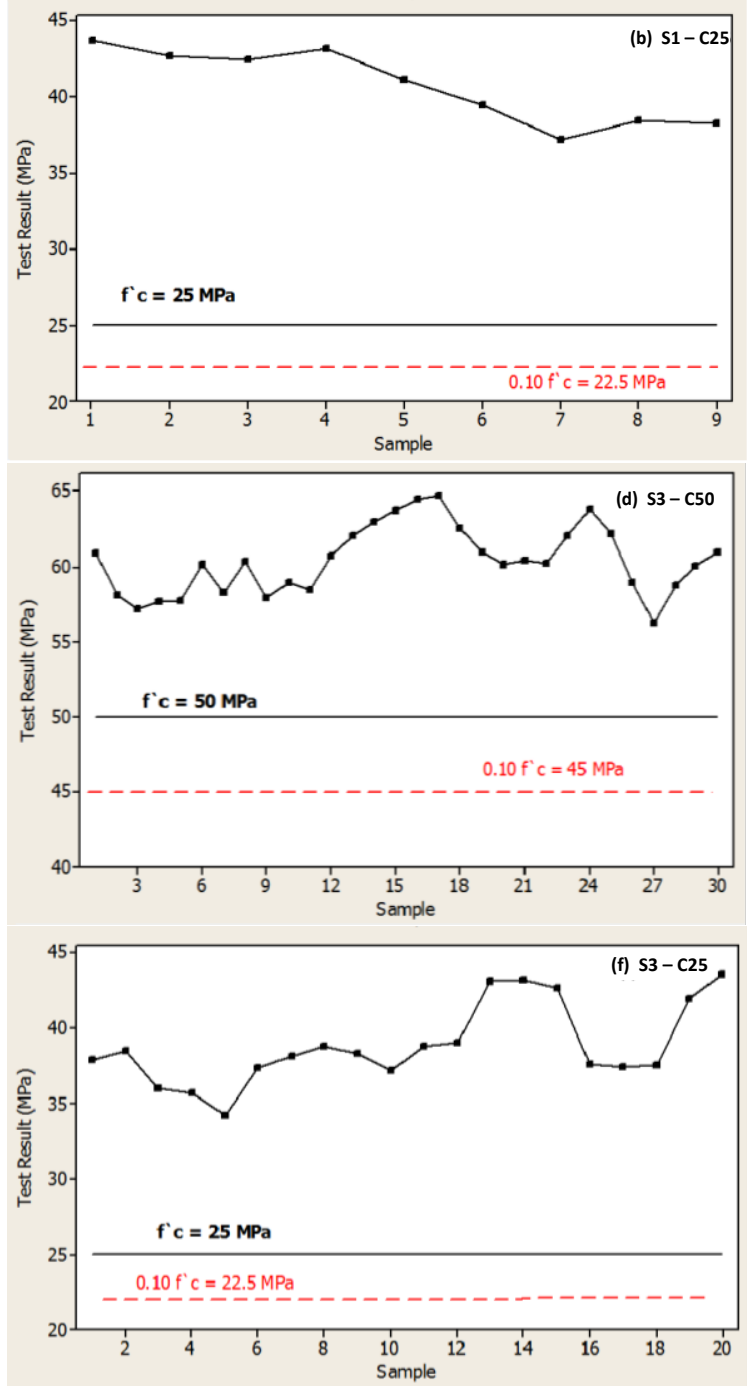

Fig. 2: Run chart of strength test results for the three suppliers

They recommended that due to the scarcity of raw materials for making concrete and penalties that can be incurred by companies, it is important to apply quality control methods to identify ways to reduce unnecessary use of materials while maintaining a high level of quality and meeting required specifications. Table 1 summarizes the statistics for the three suppliers and allows making a classification based on ACI (2005).
It can be deduced that the production processes for the three suppliers can be rated as "very good" to "excellent", except in the case of low concrete strength (C25) delivered by suppliersS1 and S3 where the high values of the coefficient of variation would indicate a relatively "poor" processes that would require some improvement.

This may be attributed to errors in estimating the standards deviation due to the small number of 


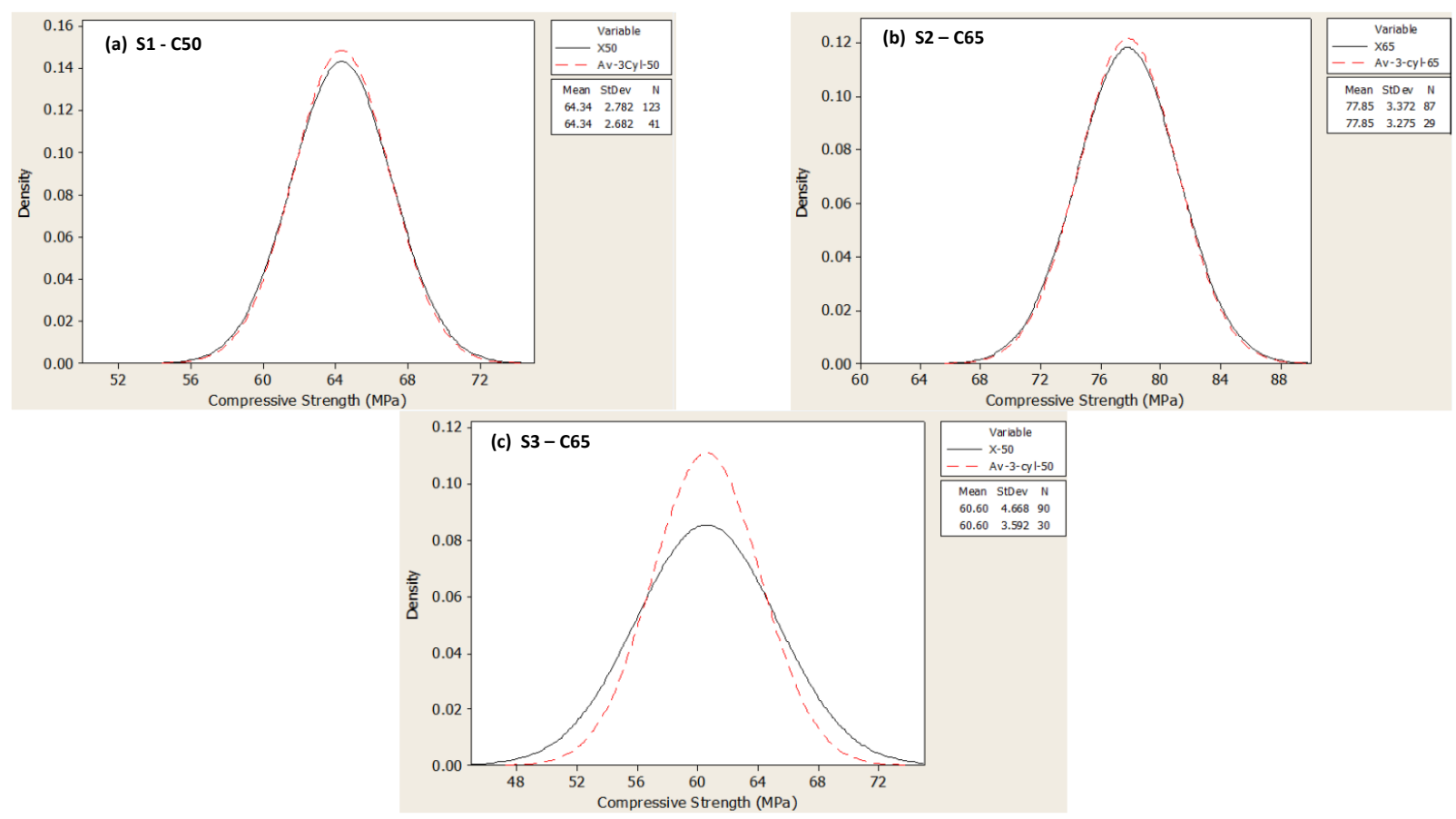

Fig. 3: Process distributions for compressive strength (data obtained from single-cylinder results and Average of three cylinders as defined by ACI (2005))

Table 1: Concrete statistics and process classification according to ACI (2005)

\begin{tabular}{|c|c|c|c|c|c|}
\hline Supplier & $\begin{array}{l}\text { Concrete } \\
\text { Type }\end{array}$ & $\begin{array}{l}\text { Mean Strength } \\
(\mathrm{MPa})\end{array}$ & $\begin{array}{l}\text { Standard Deviation } \\
(\mathrm{MPa})\end{array}$ & $\begin{array}{c}\text { Coefficient of Variation } \\
(\%)\end{array}$ & $\begin{array}{l}\text { Process Performance according to } \\
\text { ACI214R-02 }\end{array}$ \\
\hline \multirow{3}{*}{ S1 } & $\mathrm{C} 25$ & 40.035 & 3.397 & 8.49 & Poor $(*)$ \\
\hline & C50 & 64.345 & 2.782 & 4.32 & Excellent \\
\hline & C65 & --- & --- & --- & --- \\
\hline & $\mathrm{C} 25$ & -.- & -.- & -.- & -.- \\
\hline \multirow[t]{3}{*}{ S2 } & C50 & 71.922 & 4.293 & 5.97 & Excellent \\
\hline & C65 & 77.85 & 3.372 & 4.33 & Excellent \\
\hline & $\mathrm{C} 25$ & 39.282 & 4.472 & 11.39 & Poor \\
\hline \multirow[t]{2}{*}{ S3 } & C50 & 60.597 & 4.668 & 7.70 & Very Good \\
\hline & C65 & -.- & -.. & --- & -.. \\
\hline
\end{tabular}

\subsection{Process variability analysis using statistical process control (SPC)}

Statistical Process Control (SPC) or Qualitycontrol charts have been used by manufacturing industries including the construction industry for many years as aids in reducing variability, increasing production efficiency, and identifying trends as early as practicable. Well-established methods for setting up such charts are outlined in convenient form in the ASTM Manual on Presentation of Data and Control Chart Analysis, (ASTM, 2010), and international standard ISO (2011). Statistical Process control charts can be very useful in analysing process variations and identifying causes. Generally speaking, control charts are an important tool in quality management (Lobo, 2006) and help project managers and production personnel to identify if: (a) the production process in a state of statistical control, that is influenced only by "common natural causes" of variation; (b) or a non-stable out of "statistical control" process operating under "special causes" of variations. The latter would require corrective actions in order to bring back the process under statistical control. For strength concrete data,
ACI (2005) recommends the use of basic control charts such as run charts for individual strength tests, the moving average for strength and the moving average for range to monitor and control concrete strength data for ease of calculations. With the advent of computer software such as Minitab, it has become very practical for project engineers to easily create control charts recommended by ACI (2005) or suggested by other researchers (Gibb and Harrison, 2010; Sarkar and Dutta, 2009). For a given concrete type, changes in statistical parameters such as the average $(\bar{x})$, the range $(\mathrm{R})$ or the standard deviation ( $\mathrm{s}$ ) can indicate changes and variations in either the constituent raw materials or the production process components (Man, Machines, Methods, Measurements of quantities). Based on control charts, the level of control upon the concrete production process and its outcome can be apprehended through test strength measurements of concrete supplied to construction sites. Such control charts would include: (a) Individual strength control charts; (b) Shewhart control charts (e.g. $\bar{X}$-R charts, $\bar{X}$-s charts), (c) Cumulative Sum (CUSUM) and Exponentially Weighted Moving Average (EWMA) charts to detect and monitor small variations and 
identify early trends. The basic assumption prior to the use of control charts to monitor processes is that the process data is normally distributed ( $\mathrm{H}_{0}: \mathrm{Null}$ Hypothesis). The normality assumption is statistically tested and Table 2 summarises the relevant results. The normality assumption is tested using the Anderson-Darling (AD) test which is usually used to determine if a sample of data could have come from a normally distributed population (Laungrungrong et al., 2009). A lower value of the AD statistic indicates that the data follows a normal distribution. The p-values can also be used to determine the validity of the normality assumption $\left(\mathrm{H}_{0}\right)$. If the pvalue is less than or equal to the commonly chosen level of 0.05 , then there is evidence that the data are not normally distributed. Results of the $\mathrm{AD}$ test reported in Table 2 suggest that the process data follow a normal distribution. The p-values shown in Table 2 are in most of the cases greater than 0.05 . Thus, it can safely be concluded that the concrete strength data come from a normally distributed production process. If, in contrast, the distribution is not normal, the conclusions drawn from control charts on the stability of the process may be misleading and erroneous. In this case, an alternative approach based on the identification of the best distribution that would fit the data (log-normal, Weibull, exponential, Johnson's distribution) can be used (Aichouni et al., 2014). This best distribution can be used as a model to normalize the concrete strength data that originally showed departure from normality.

Once the normality of the concrete strength data is tested, further analysis can be carried out to investigate statistical stability and control of concrete production processes for the three suppliers. As recommended by ACI (2005) and ISO (2011) process control is performed using the following control charts in the sequencing order:

a) Individual and Moving Range Charts for Strength test results;

b) Shewhart $\bar{X}$-R charts for all individual cylinders results;

c) CUSUM and EWMA chart for all individual cylinders results.

The individual and moving range control charts are generally used to monitor variations in strength test results, defined as the average of three singlecylinder strengths of specimens made from the same concrete sample (companion cylinders) and tested at the same age (28 days). Similarly to Shewhart control charts $(\bar{X}-\mathrm{R}, \bar{X}$-s); individual charts are efficient to detect large variations in concrete characteristics. When only small variations exist, use of CUSUM and EWMA charts will be more appropriate. $(\bar{X}-\mathrm{R})$ charts, CUSUM and EWMA will deal with the results of single-cylinder strengths.

Table 2: Statistics for Normality Test Results for the concrete data

\begin{tabular}{|c|c|c|c|c|c|c|c|}
\hline Supplier & $\begin{array}{l}\text { Concrete } \\
\text { Type }\end{array}$ & $\begin{array}{l}\text { Mean Strength } \\
(\mathrm{MPa})\end{array}$ & $\begin{array}{c}\text { Standard Deviation } \\
(\mathrm{MPa})\end{array}$ & $\mathrm{N}$ & $\mathrm{AD}$ & $\mathrm{p}$ & $\begin{array}{c}\mathrm{H}_{0} \text { : data follow the Normal } \\
\text { distribution }\end{array}$ \\
\hline \multirow{3}{*}{ S1 } & $\mathrm{C} 25$ & 40.04 & 3.397 & 27 & 0.546 & 0.146 & Accept Ho \\
\hline & $\mathrm{C} 50$ & 64.34 & 2.782 & 123 & 1.935 & $\leq 0.005$ & Reject Ho \\
\hline & C65 & --- & --- & --- & --- & --- & --- \\
\hline \multirow{3}{*}{$\mathrm{S} 2$} & $\mathrm{C} 25$ & --- & --- & --- & --- & ---- & --- \\
\hline & $\mathrm{C} 50$ & 71.92 & 4.293 & 72 & 1.89 & $\leq 0.005$ & Reject Ho \\
\hline & C65 & 77.85 & 3.372 & 87 & 0.091 & 0.019 & Accept Ho \\
\hline \multirow{3}{*}{ S3 } & $\mathrm{C} 25$ & 39.28 & 4.472 & 60 & 0.514 & 0.186 & Accept Ho \\
\hline & $\mathrm{C} 50$ & 60.60 & 4.668 & 90 & 0.581 & 0.127 & Accept Ho \\
\hline & C65 & --- & --- & --- & --- & --- & --- \\
\hline
\end{tabular}

Minitab outputs for the control charts categories for the three concrete suppliers are shown in Figs. 4, 5 , and 6. These figures represent the process variability in concrete strength delivered to the projects. The general observations that can be drawn are:

Individual moving range charts (based on the average of three cylinders) shown in Fig. 4; do not exhibit any out of control situation for the three concrete suppliers. This would mean that the production processes for the suppliers are "under statistical control" and "stable". Such conclusion would reinforce early observations of "good" to "excellent process control" made when discussing process distributions and concrete classification according to ACI (2005) (section 3.3.2).

$(\bar{X}-\mathrm{R})$ charts shown in Fig. 5 indicate that concrete production processes were "out of statistical control" for the three suppliers. This leads to believe that there are some assignable causes that affect concrete strength variability. The C50 concrete
Strength supplied by supplier S3 (Fig. 5c) exhibits less variability, indicating that only normal variations are affecting the production process.

The CUSUM and EWMA charts shown in Fig. 6 and 7 respectively clearly identify some significant trends in concrete strength characteristics for suppliers S1 and S2 (Figs. 6a, 6b, 7a, and 7b) due to some special causes affecting the production process. The charts obtained for supplier S3 (Figs. 6c and $7 \mathrm{c}$ ) show less variability indicating that the production processes are operating "under statistical control state".

Out of control situations shown by $(\bar{X}-\mathrm{R})$, CUSUM and EWMA charts can be viewed as indications of the existence of multiple sources of special causes of variations in the concrete production processes for suppliers S1 and S2.

The statistically proven "out of control" observations should be considered as opportunities for improvement in the concrete production processes. Possible causes for process statistical 
instability can be investigated using root-cause analysis within brainstorming sessions grouping both contractor quality management and production

(a) S1
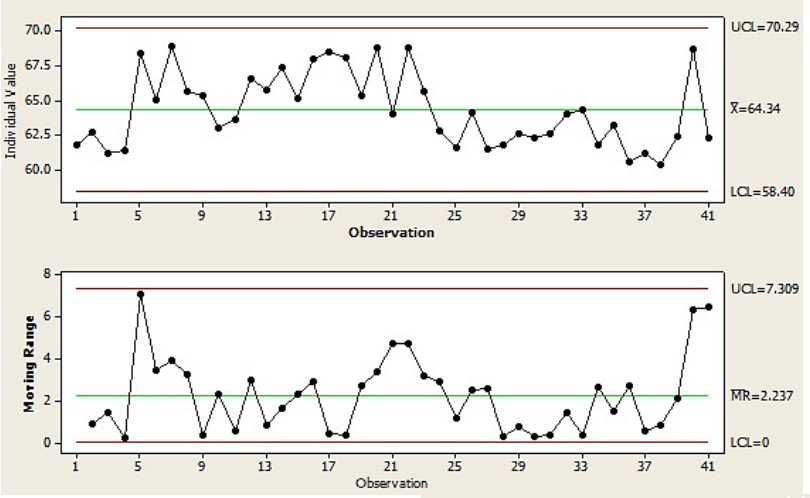

departments. Fig. 8 shows an example of fishbone diagram to analyse root causes of out of control concrete processes.

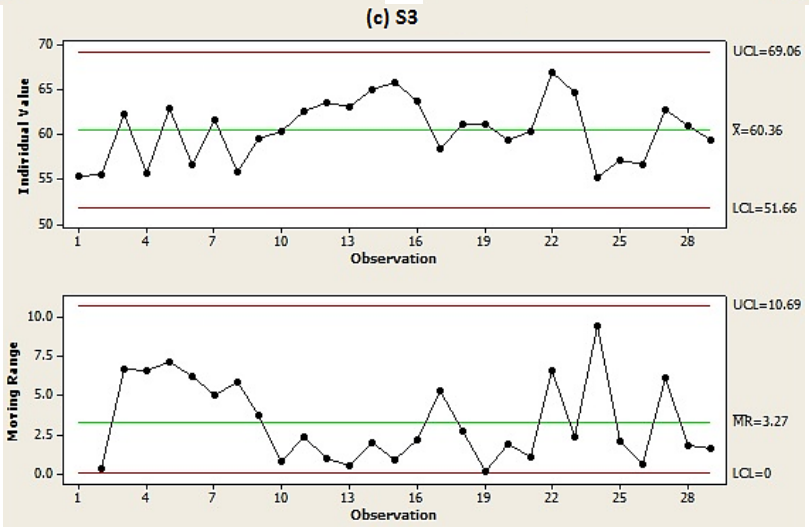

Fig. 4: Individual and moving range charts for concrete from the three suppliers
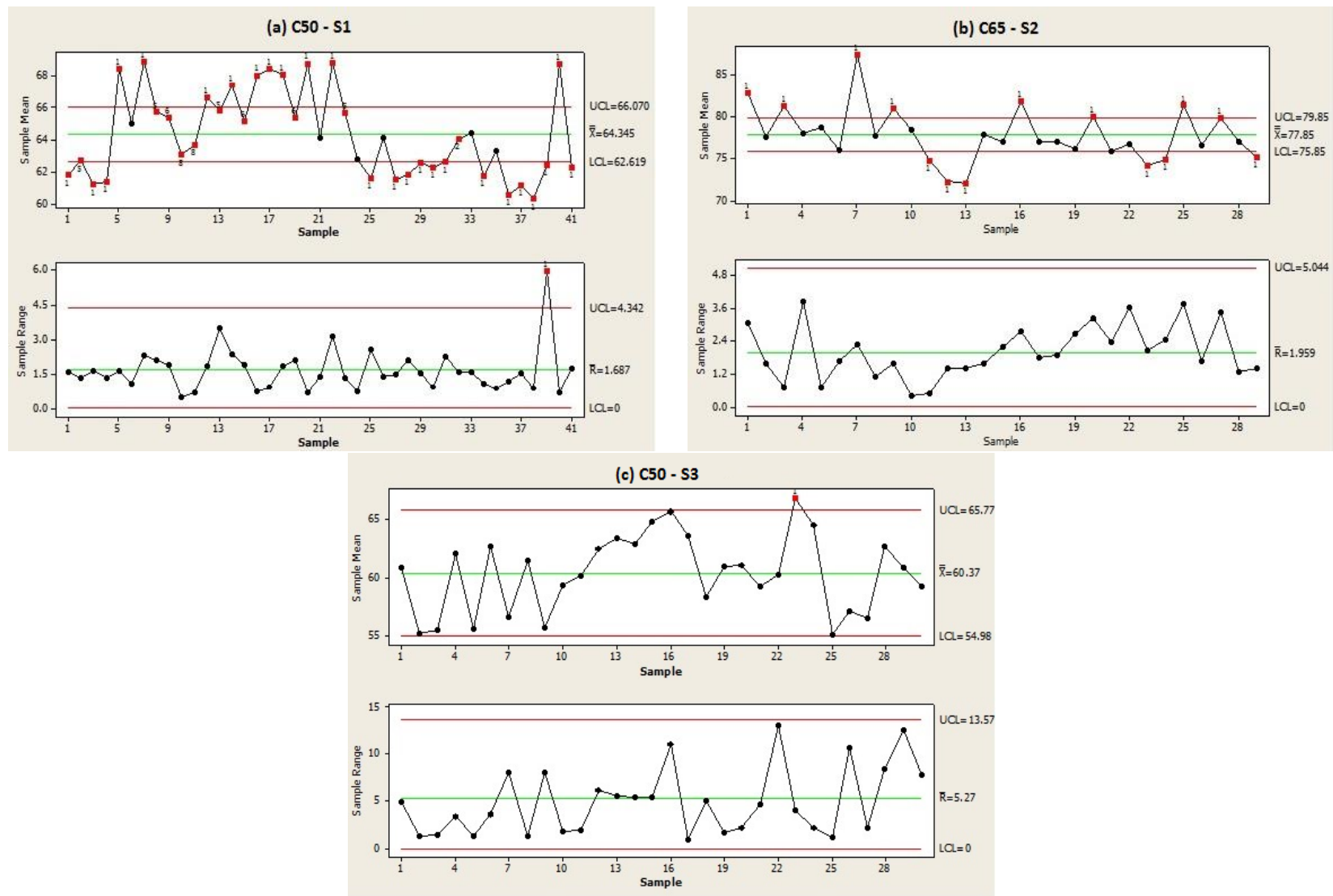

Fig. 5: Shewhart $\bar{X}$-R charts for all individual cylinders results for concrete from the three suppliers

It should be noted here that none of the three concrete suppliers used control charts as tools to monitor concrete strength characteristics. Only individual strength charts were used. The $\overline{\mathrm{X}}-\mathrm{R}$, 
CUSUM and EWMA charts have not been used for analysing strength variations though clearly indicated in international standards such ACI (2005). The Saudi Building Code (SBC, 2007) does not consider this issue.
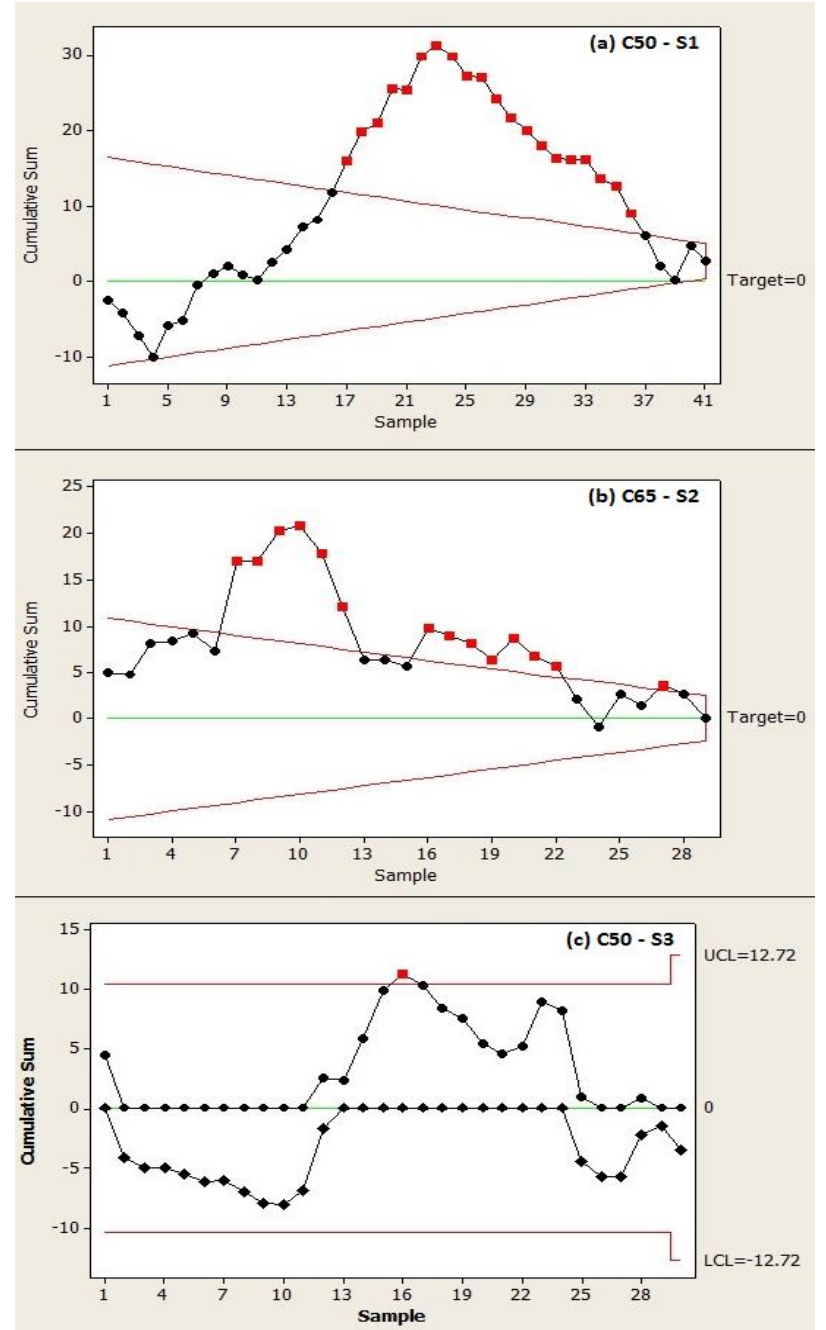

Fig. 6: CUSUM charts for concrete from the three suppliers

\section{Conclusion}

The present work presents a short review of international standards concerning the evaluation of strength test results of concrete (SBC. 2007; ACI, 2005), and sets a practical procedure that allows construction firms to perform statistical analysis of strength results for concrete conformity evaluation and process improvement. The research is mainly based on the statistical evaluation of concrete strength results of three concrete suppliers to an important Saudi construction. From the statistical analysis of the concrete strength results performed by accredited third parties, the following conclusions can be formulated:

As far as the compliance with design and contract specifications, the concrete delivered by the three suppliers to the project, meets the specifications of the Saudi Building Code (SBC, 2007) and ACI (2005).

The individual moving range charts obtained for the average of three cylinders from the same batch, showed an "under statistical control" and "stable" processes, while more accurate and sensitive control charts such as $\bar{X}$-R, CUSUM and EWMA would suggest that the concrete production processes exhibit "out of statistical control" situations especially for suppliers S1 and S2, indicating that production processes are "instable" and operating under "special causes of variations".
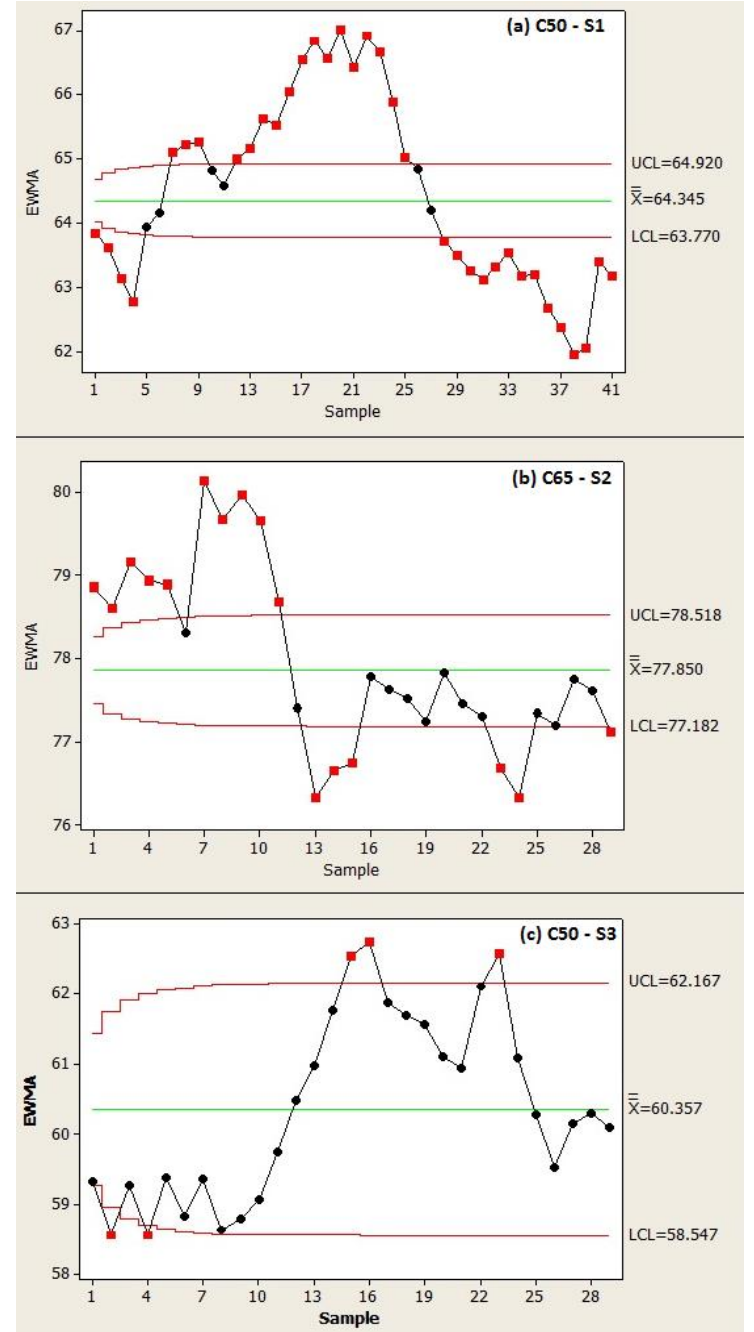

Fig. 7: EWMA charts for concrete from the three suppliers

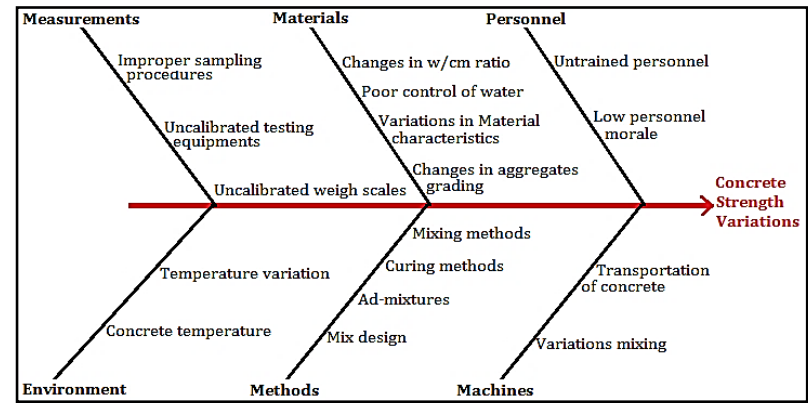

Fig. 8: Example of root causes analysis for concrete strength variations

The process instability detected by control charts should be considered as an opportunity for improvement in the concrete production processes. Root Causes Analysis (RCA) should be performed using proven methods and tools within brainstorming sessions grouping the contractor 
quality management department and the suppliers' production departments.

In order to improve concrete production processes, management should set systematic procedures using quality tools such as histograms, control charts and fishbone diagrams, to analyse concrete strength data and detect any abnormal variation.

Corrective actions should be taken to remove the special causes of variation from the process and to reduce its variability. The roadmap for process improvement proposed in the present work can be used by concrete suppliers to detect variability problems and achieve breakthrough improvement toward more economical and sustainable concrete production processes.

The Saudi Building Code (SBC, 2007), devotes section 5.6 to the evaluation and acceptance procedures of concrete. Nevertheless, the code can be complemented by addressing the issue of evaluating strength variations and process classification as regards to the performance of concrete production similarly to other international standards such as ACI (2005) (section 3). Furthermore, precise guidelines should be included regarding specific statistical tools and methods that should be used in such evaluation.

\section{Acknowledgment}

This work is undertaken at the College of Engineering of the University of Hail within the "Muallem Mohamed BinLadin Research Chair on Quality and Productivity Improvement in the Construction industry" sponsored by Saudi Binladin Group. This support is gratefully acknowledged by the research team. The contents of this article reflect the views and opinions of the research team members who are responsible for the facts and accuracy of the data presented herein.

\section{References}

ACI (2005). Committee 214: Evaluation of strength test results of concrete (ACI 214R-02). American Concrete Institute, Manual of Concrete Practice, Farmington Hills, USA.

Aichouni M, Ait-Messaoudenne N, Al-Ghonamy A, and Touahmia M (2014). An empirical study of quality management systems in the Saudi construction industry. The International Journal of Construction Management, 14(3): 181-190.
ASTM (2010). ASTM MNL7: Presentation data and control chart analysis. $6^{\text {th }}$ Edition, ASTM International, West Conshohocken, Pennsylvania, USA.

ASTM (2015). ASTM C31: Standard practice for making and curing concrete test specimens in the field. ASTM International, West Conshohocken, Pennsylvania, USA.

ASTM (2017). ASTM C39: Standard test method for compressive strength of cylindrical concrete specimens. ASTM International, West Conshohocken, Pennsylvania, USA.

Banawi A and Bilec MM (2014). A framework to improve construction processes: Integrating lean, Green and six sigma. International Journal of Construction Management, 14(1): 4555 .

Chen X, Wu S, and Zhou J (2014). Variability of compressive strength of concrete cores. Journal of Performance of Constructed Facilities, 28(4): 1-6.

Day W, Aldred J, and Hudson B (2013). Concrete mix design, quality control and specification. CRC Press, Boca Raton, USA.

De Stefano M, Tanganelli M, and Viti S (2014). Variability in concrete mechanical properties as a source of in-plan irregularity for existing RC framed structures. Engineering Structures, 59: 161-172.

Dias S and Saraiva PM (2004). Use basic quality tools to manage your processes. Quality Progress, 37(8): 47-53.

Gibb I and Harrison T (2010). Use of control charts in the production of concrete. European Ready Mixed Concrete Organization (ERMCO), Brussels, Belgium.

ISO (2011). ISO 13053-2: Quantitative methods in process improvement-Six Sigma-Part 2: Tools and techniques. International Organization for Standardization, Geneva, Switzerland.

Laungrungrong B, Mobasher B, Montgomery D, and Borror CM (2009). Hybrid control charts for active control and monitoring of concrete strength. Journal of Materials in Civil Engineering, 22(1): 77-87.

Lobo CL (2006). Control Charts: An important tool in quality control to save money. Concrete in Focus-NRMCA, 4(4): 1516.

Obla k (2010). Sources of your concrete strength variation-part II of concrete quality control series. Concrete in Focus, 9(4): 2123.

ReVelle JB and Margetts DN (2010). Home builders guide to continuous improvement: schedule, quality, customer satisfaction, cost and safety. CRC Press, Boca Raton, USA.

Sarkar D and Dutta G (2009). Design and application of risk adjusted cumulative sum for strength monitoring of ready mixed concrete. Journal of Construction Engineering and Management, 136(6): 623-631.

SBC (2007). SBC 304: Saudi Building Code Structural Requirements commentary for concrete structures. Saudi Building Code, Riyadh, Saudi Arabia. 